\title{
Serious Adverse Experience
}

National Cancer Institute

\section{Source}

National Cancer Institute. Serious Adverse Experience. NCI Thesaurus. Code C142686.

A situation referring to a severe reaction, risk or indication ag ainst use of a treatment or device. 